\title{
A Conceptual Framework of Displaced Elderly Syrian Refugees in Lebanon: Challenges and Opportunities
}

\author{
Lama Bazzi ${ }^{1}$ \& Zeina Chemali ${ }^{2}$ \\ ${ }^{1}$ Department of Psychiatry, SUNY Stony Brook Medical Center, Stony Brook, New York, United States \\ ${ }^{2}$ Department of Psychiatry and Neurology, The Chester Pierce Division of Global Psychiatry, Massachusetts \\ General Hospital, Boston, Massachusetts, United States \\ Correspondence: Zeina Chemali, Department of Psychiatry and Neurology, The Chester Pierce Division of \\ Global Psychiatry, Massachusetts General Hospital, 15 Parkman St., WACC 815, Boston, MA 02114, USA. Tel: \\ 1-617-724-5600. E-mail: zelchemali@mgh.harvard.edu
}

Received: October 19, 2015 Accepted: February 16, 2016 Online Published: February 29, 2016

doi:10.5539/gjhs.v8n11p54 URL: http://dx.doi.org/10.5539/gjhs.v8n11p54

\begin{abstract}
In the context of ongoing armed conflicts, efforts to provide humanitarian care are often not sustainable or effective in the long run. Additionally, there is a significant gap between interventions that are theoretically feasible and those that are actually implemented in practice. Building on these foundations and challenged by the limited publications on Syrian refugees, especially the elder population, we explore the understudied connection between the day to day elder refugee experience on one hand and the lack of building resources from within on the other. We take the example of Lebanon, where as many as 4000 Syrian refugees crossed into its territory daily and which now has the highest number of refugees per capita in the world. Lebanon has limited resources and funding and is strained under this socioeconomic burden. Due to this harsh reality, refugees' simplest needs are largely unmet and they are easy targets for retaliation by local civilians competing for basic resources. Needless to say, elderly refugees suffer most from these inequities and their status is particularly vulnerable. Within this context, and based on ongoing fieldwork, we offer a conceptual framework which calls for effective and sustainable interventions nurturing resilience in elderly refugees and ultimately aiming to help decrease tensions between the host communities and refugees.
\end{abstract}

Keywords: Syrian refugees, elders, Lebanon, resources, host community, vulnerable group

\section{Introduction}

\subsection{The Syrian Crisis}

The United Nations (UN) has acknowledged that the Syrian Civil War is the worst humanitarian crisis to date, surpassing even the horrors of the 1994 Rwandan genocide (UN says Syria refugee crisis worst since Rwanda, 2013). While the conflict in Syria rages on, civilians continue to be displaced. On a daily basis, over 6000 refugees continue to flee Syria and recognize that Syria is not likely to be in a position to welcome its people back in the foreseeable future. Over 4.5 million Syrian have fled their country (UNHCR, 2016). Although UN Refugee Chief Antonio Gutteres stated that surrounding countries' acceptance of Syrian refugees saved the refugees' lives, he acknowledged the "crushing" effects that the overwhelming numbers of refugees have had on the host countries (UNHCR, 2013). At one point, over 4000 of those refugees crossed into Lebanon on a daily basis making up 25 to $40 \%$ of the small country's population, and straining its already fragile social, political, geographic, and economic infrastructure (Dahi, 2013).

Over 50 percent of Syrian refugees in Lebanon are children and the vast majority have no access to education, housing, or basic medical care. Only 13\% of the Syrian refugee children are enrolled in schools (Mercy Corps, 2016; The UN refugee agency, 2015). Lebanon does not cover non-urgent medical care for Syrian refugees, with the Higher Relief Council citing lack of funding and limited resources as their reasons to sanction care (IRIN News Middle East, 2012).

To make matters worse, over half of the Syrian refugees now live in unstable dwellings. The Lebanese government is reportedly highly resistant to setting up formal refugee camps, as the volatile and unpredictable Palestinian refugee camps are a foreboding presence in Lebanon that cannot be ignored (IRIN News Middle East, 
2012; Crisis Group, 2013; Amos: Syrian Refugees Make up 25 to 30 Percent of Lebanon's Population, 2015; IRIN News Middle East, 2012; Hodeib, 2014). In addition, in January 2014, the Lebanese Government introduced a new visa requirement asking Syrians to list the reasons why they are in Lebanon. The reasons are detailed in six categories, though no category is explicitly for refugees (Harissi, 2015).

Without housing, education, food, and medical care, the rapidly increasing Syrian refugee population will continue to struggle. The temporary measures set up for refugees in Lebanon are no longer adequate or sustainable (Amos: Syrian Refugees Make up 25 to 30 Percent of Lebanon's Population, 2015). Tensions between the host communities, most in the poorer regions of Lebanon, and the refugees are mounting, and threaten the already fragile Lebanese political stability (Nebehay, 2014; Ballout, 2015). More than 90\% of Lebanese citizens polled, felt that Syrian refugees should not be mixing with Lebanese communities and many felt the Syrians should return to their own country. Unless efforts are made to identify and implement culturally sensitive approaches to easing hostility and diffusing tensions between the two populations, open violence and war will become unavoidable (Shreif, 2014).

\subsection{Ageism and the Needs of Elderly Refugees}

Robert Butler coined the term "ageism" in describing how society discriminates, as a whole, against the elderly, diminishing their collective worth to society and ignoring their potential contributions to its betterment. He described ageism as "the prejudicial attitudes towards the aged...the aging process." He noted that ageism included "discriminatory practices against the elderly...in social roles..." He went on to explain how policies tend to "perpetuate stereotypic beliefs about the elderly..." even without meaning to harm the elderly (Butler, 1983). In Lebanon, the current approach to the Syrian refugee population fosters what Butler (1983) described as institutional ageism. Although the individual social workers, doctors, and staff of Nongovernmental Organizations (NGOs) providing Syrian refugees with services may not discriminate against people because of their age, the way resources are distributed neglects the aged and favors the young. Although there are countless references to the vulnerable children amongst the Syrian refugees in Lebanon, relatively few acknowledge the elderly and frail among them (McConnell, 2014).

Older refugees from Syria are a highly vulnerable population in need of health surveillance and targeted assistance. Most programs during time of conflict or crisis prioritize assistance to vulnerable populations in services on women and children leaving the elderly overlooked and marginalized (Strong, Varady, Chahda, Doocy, \& Burnham, 2015). Elderly refugees, like refugees before them, arrive to the host country with multiple issues including untreated chronic medical conditions such as diabetes and hypertension, have not received adequate preventative healthcare, and suffer from severe mental distress (Cultural Orientation Resource Center, 2014). With the United Nations High Commission for Refugees, the UN's Refugee Agency (UNHCR) limiting funds available for chronic diseases, including cancer and kidney dialysis, the medical needs of elderly refugees are often overlooked in favor of treating younger patients (United Nations High Commission for Refugees, 2014). Furthermore, the needs of the elderly for daily medications and preventative medical care are not met and their needs of medications and medical care are not met in Lebanon (Coutts, Fouad, \& Batniji, 2013).

Indeed, when Syrian refugees' needs were assessed $66 \%$ of them rated their own health as poor or very poor. One third reported having cardiac disease while $60 \%$ had high blood pressure. Almost $90 \%$ said that they did not have access to medications. Over $60 \%$ of the elderly refugees self-reported anxiety, depression, guilt, and feeling like a burden to their families (Strong, Varady, Chahda, Doocy, \& Burnham, 2015).

Furthermore, when taking into consideration the unsanitary conditions in makeshift camps, the visual and mobility constraints that elderly patients may have, and the environmental risks of dehydration and malnutrition, elders are particularly vulnerable In addition, many have cognitive deficits to begin with, making it difficult to understand and assimilate new medical care information. There are also few resources available to them to address their neurological and psychological needs (From the field: Syrian refugees in Lebanon risk their lives for medical treatment, 2014).

\subsection{The Role of the Elderly Refugee}

Francis Kariuki, an attorney with the Chartered Institute of Arbitrators, has written extensively on the role of the elderly citizen in mentoring and guiding younger members of society (Kariuki, n.d.). The manner in which African communities are structured is similar to the way Lebanese and Syrian societies are built. Family members are expected to care for the elderly in their family, to preserve family structure, and to avoid placing elders in nursing homes and assisted living facilities whenever possible..Although schools are opening afternoon classes for some Syrian refugee children, many young members of the refugee community remain idle and feel they have no purpose. With limited freedom to move around the country, few resources, and fewer opportunities, 
unrest and violence become inevitable. As Elders are viewed as the keepers of family structure and pride, one can easily see their pragmatic role in shaping a peaceful younger generation with wise and respected role models (Kariuki, n.d.).

\subsection{Empowering the Elderly Refugee}

To date, little research has been conducted looking into the role the elderly play in Middle Eastern societies in general. Furthermore, there are few programs in Lebanon that target educating or empowering the elderly in any capacity. Among refugees, we see an opportunity to learn from the elderly Syrian refugees in Lebanon. Our work spanning 2014-2016 will be published at its completion. Through it all, we identified gaps in the refugee care including medical and psychological deficits affecting their wellbeing. Today, we offer as first publication a conceptual framework, which calls for an effective and sustainable intervention nurturing resilience in elder refugees and helping to decrease tensions between the host communities and refugees.

\section{Methods}

\subsection{Background and Literature Review}

We conducted a literature review of the United States National Library of Medicine National Institute of Health biomedical literature database, PUBMED. We used the following keywords in conducting our search: Elderly, Syrian, Refugee, Lebanon. We were attempting, in our work on the Syrian elder refugee community, to understand issues from the perspectives of the refugees themselves. We were striving to analyze the contexts in which those issues arise, identify root cause of their problems and highlight opportunities to intervene for peace and to empower the elders in the Syrian refugee communities. As such, we conducted a review and analysis of relevant articles published in Middle Eastern journals and newspapers, which clarified and exposed the context and details of the everyday lives of Syrian refugees in Lebanon.

\subsection{Ground activity with the Elderly Refugees}

In a recent study (currently in review and detailed elsewhere) and in partnership with Lebanese fieldworkers from the Ministry of Social Affairs (MOSA) Syrian Project, we surveyed elders in dwelling encampments of El-Marj and Bar Elias in Lebanon. Briefly, the participants were randomly selected from a pool of elderly Syrian refugees who consented with MOSA representatives to be part of the intervention. We asked them semi-structured survey questions eliciting details of their quality of life, well-being and cognitive status. Six questions akin to the Geriatric Depression Scale (GDS) in Arabic were embedded in the survey. The GDS is a series of questions that have are highly sensitive and specific for the diagnosis of depression. The GDS is usually employed as part of a comprehensive geriatric evaluation (Sadavoy, Lazarus, Jarvik, \& Grossberg, 1997). A Brief Cognitive Impairment Scale (BCIS) was also randomly administered to participants. The BCIS is a short test that is administered to patients to identify deficits in executive functioning, language, and memory. It can detect mild dementia as well as more advanced cases of dementia (Krishnan et al., 2001). The survey, including the modified GDS, was administered to a total of 66 participants, while the BCIS was administered to a total of 34 participants. Of note, the social and fieldworkers who took part of this survey-field visit were trained by the authors on Relaxation Response Resilience Program-3RP SMART program translated and adapted into Arabic (The Benson Henry Institute 3 RP SMART Program, 2016; Park et al., 2013). The SMART program teaches self-care and empathy, builds resilience to improve mental and physical health of the fieldworkers and contributes to fostering a connection between the host communities and the refugees. The results of the 3-RP SMART Training Program and the fieldwork that followed are currently being separately prepared for publication.

\section{Results}

\subsection{Literature and News Article Review}

The search of the United States National Library of Medicine National Institute of Health biomedical literature database, PUBMED, yielded seven articles. Of the seven articles, only one addressed the health status and needs of elderly Syrian refugees in Lebanon (Strong, Varady, Chahda, Doocy, \& Burnham, 2015). One article focused on the nutritional status and needs of Syrian refugee women and children (Bilukha et al., 2014). One article discussed the reproductive health and domestic violence rates among Syrian woman refugees in Lebanon (Reese Masterson, Usta, Gupta, \& Ettinger, 2014). The other articles were either related to Palestinian refugees residing in Lebanon or completely unrelated to the status of refugees in Lebanon.

A review of relevant news articles offered more insight into the different players governing the conditions that Syrian refugees are facing in Lebanon. The complexity of the human migration crises is ethical, economic and political. The root causes are complex and include persecution for many reasons including race, religion, nationality, and gender, as well as belonging to a social group or gravitating towards groups with particular 
political opinions. Furthermore, human migration is halted by local, regional and global political stalemates. Rising inequality and poverty propel people, including elders, to seek better futures elsewhere. Naturally, addressing the underlying systemic issues takes more time, effort and political maneuvering, but with proper execution, can benefit both the host communities and the refugees (Ballout, 2015; From the field: Syrian refugees in Lebanon risk their lives for medical treatment, 2014; McConnell, 2014).

\subsection{Assessing the Needs and Concerns of Syrian Elderly Refugees}

The literature reviewed was significant for a paucity of data addressing the needs and concerns of the elderly among Syrian refugees. Some articles did speak of some challenges faced by the elders, including a lack of available medical care, and mental health issues that have gone largely unaddressed (McConnell, 2014). We considered the lack of available information identifying the needs of elderly refugees in designing our project to assess the needs of this vulnerable and underserved faction of the Syrian refugee community.

Along with Lebanese fieldworkers from the Syrian Project, we surveyed elders in dwelling encampments of El-Marj and Bar Elias in Lebanon on their quality of life, well-being and cognitive status. Six questions akin to Geriatric Depression Scale (GDS) in Arabic were embedded in the survey. A Brief Cognitive Impairment Scale (BCIS) was randomly given to participants. The results are still pending and will be published separately, but preliminary data analysis indicate that over $80 \%$ of participants were depressed and over $40 \%$ showed cognitive deficits.

As for the emerging themes in the qualitative section, they centered on the importance of family connectedness in fostering a sense of security and normalcy for the day to day lives of the elders. Elders enjoyed telling stories to family members, participating in simple chores, and fostering a sense of normalcy for their community members. The more loving and supportive the family members were, the more resilient and confident the elders. The elders worried about their health and about needing hospitalization. They worried about dying in exile, as well as worried about the burdens they represented to their families. Many voiced wanting to return home. Elders expressed concern over crowded living conditions, lacking safety measures, and a lack of resources available to them. They also mentioned that medications for chronic conditions, including diabetes, hypertension, and cardiac problems, being difficult to obtain. Elders spoke of their role in the community as being similar to that of the social workers with whom they interacted. Although they expressed gratitude to the social workers for providing them with tangible services needed in their everyday lives such as tents and food, they expressed a desire to be a source of emotional support and a community cornerstone for those around them.

\section{Discussion}

Our results highlight a paucity of research identifying the needs and challenges facing elderly Syrian refugees. The literature that exists highlights the limited options that the elderly have in times of war and as potential refugees. Many risk death because they hesitate to leave the communities they consider to be their homes. One study highlighted the mental and physical health status of Syrian refugees in Lebanon. They found that most of the elders estimated that their health was poor or very poor. They reported having difficulties ambulating, visual constraints, and reported poor nutrition. They did not have access to medications they needed for chronic conditions, including hypertension and cardiac disease. Elders felt like they had lost some of the esteem they held in their communities in Syria, and implicated a disruption in family and societal structure for this change in status (Strong, Varady, Chahda, Doocy, \& Burnham, 2015).

We understand that conducting research amidst ongoing conflict and political instability is often overtaken by the urgent needs of the population. Nevertheless, we stress that without conducting sufficient basic needs assessment, individuals and organizations cannot run successful operations to understand the root cause of the problem, nor can they successfully help from within to solve the problems. With scarce resources and even scarcer funding, efficient allocation of said resources can only be accomplished after we properly understand the needs of the community the organizations are attempting to help (Harvard Humanitarian Intitiative, 2014). We highlight that research on the status of Syrian elderly refugees is scarce, and that very little light has been shed on the role this vulnerable population plays in the stability of the Syrian communities in Lebanon. This reality pushed us after visiting Syrian refugees in Lebanon to advance a conceptual framework based on a practical reality. As we know, the major determinants for health are not necessarily addressed by healthcare alone, as they include the presence of structural violence, war, conflict, education and social justice. The main determinants of health are altogether outside the realm of healthcare as we traditionally understand it (World Health Organization, 2008). By understanding local illness models and cultural idioms and norms, we can develop competent, sustainable and effective interventions.

Refugee quotidian life is plagued by chronic adversity due to forced migration and unmet basic needs. The 
mental health needs of Syrian refugees in Lebanon are, for the most part, completely unaddressed, and the resources available to them are minimal (Abou-Saleh \& Hughes, 2015). Moreover, the social fabric of society, especially tribal society as closely knit as Syrian communities, is torn apart by the conflict, and many Syrian families have become isolated from their usual support structures such as family, friends, and community (Laskowski, 2015). Our survey found that elders are longing to act as "role model social workers" for their community. Empowering elders and elder counsel is one way to go beyond clinical services and include efforts to strengthen non-clinical interventions and coping mechanisms available to members of the refugee communities.

In Lebanon and Syria, individuals identify their loyalty as lying with their family above religion, country, ethnicity, and political party. Families in the region tend to be extended and it is not uncommon for several generations to live under one roof. As such, the grandparents and elders in the family are placed on a pedestal and are turned to in times of need for leadership and guidance. Elders who left Syria as refugees often did so to avoid having their children and grandchildren travel alone and saw themselves as the keepers of the family unit (USA International Business Publications, 2012). According to our results, elders consider themselves to be integral to their society, and they long to help others in their communities. Our results further demonstrate that elders feel that remaining close to their family members is important, because it maintains a sense of security and hope for them, and allows them to maintain their purpose within the family structure. This maintenance of the core family structure amidst the chaos of displacement and being refugees gave elders strength and purpose, and above all, it enabled them to inject hope into the dire situation they found themselves living in. One pragmatic and immediate option would be to work and empower Syrian elder refugees to take their place in their community

Healthy elders should be empowered to be part of a support system set up for the community. Story-telling, playing games, and talking about the situation at large can help community members process the trauma of displacement and can serve as a vehicle for positive change. Healthy elders can be encouraged to form "elder councils" available to guide young men in making decisions that relate to the future of Syrians in Lebanon. When populations are displaced, all aspects of their day to day existence are disrupted, which elders in our interviews attested to. The elders can help rally the younger generations, engage community members, and build trust between the host community and the refugees. As has been discussed by other researchers, the implementation of elder councils can play in easing sectarian tensions, promoting peace and dialogue among members of different religious groups, and offering sound social judgment (Snyder, 2011). Furthermore, elder councils can be trained and charged with the arbitration of disputes, such as the labor disputes between the Lebanese and Syrians. While the Lebanese hosts feel bitterly about the low cost of Syrian labor, the refugees are desperate for work and will take whatever work is available to them. Appointing elder councils to mediate negotiations can dispel animosity and improve communication between Lebanese laborers, Syrian refugees looking for work, and employers looking to cut labor costs (Ballout, 2015).

Given this practical background, a conceptual framework is emerging where elders and elder care should be seen as fundamental pillars of the long-term policy response to the crisis in Syria. This focus on elders as a resource to Syrian refugee communities should be prioritized along with economic issues, governance, and rule of law issues The presence of a large, semi-permanent Syrian refugee population in Lebanon has long-term implications that must be considered on political, humanitarian, economic, and social fronts. Short-term, narrowly focused interventions that do not take into account planning for the future needs of Syrian refugees and the development of policies that will govern the rebuilding of post-conflict Syria are bound to fail.

\section{Conclusion}

The civil war that continues to rage in Syria represents an unprecedented humanitarian disaster that threatens to spill into neighboring regions. Of all the Middle Eastern countries, the smallest, Lebanon, has absorbed almost $40 \%$ of all refugees and to date has the highest number of refugees per capita, even after considering the number of Syrian refugees that fled to Europe. Focusing attention on the status of the elderly refugees and providing them with social work roles in their communities would provide the refugee population with more stability, would bring additional security to the host community, and would offer the Lebanese government tighter control over a volatile situation. Fostering leadership roles for Syrian elders in their communities would also offer the refugees a sense of agency, governance and protection in their new environment. With respect to the recent crime waves that have erupted in some of the host communities, perpetrated by refugees, the elders could provide guidance and an ethical compass to their own communities. Until then, we only perceive them as sick and unhealthy, instead of seeing them as an untapped resource with much potential. Elder refugees, with their abilities to be role models and their wisdom, can be employed, or volunteer, as pillars in safe spaces protecting 
the refugees in need of safe passage, especially in the first stages of leaving Syria. Such protection is an ethical and moral responsibility, and as strong ethical compasses for their communities, elders are natural leaders in this regard. Community members could be encouraged to train their elders to take on leadership roles, and then this responsibility could be partially shouldered and shared by other communal groups, the government, and NGOs. Finally, making the health of the elderly Syrian refugees a priority would be a first step in empowering them to become pivotal during the Syrian displacement and after the conflict resolves. This intervention would highlight better communication and peaceful collaboration between the communities, not to mention the positive impact it will have on Syrian elder refugees' mental and physical health as they feel a sense of purpose and instill hope. Our paper offers this framework as a feasible, sustainable, culturally sensitive, and effective concept. We invite the humanitarian field and other researchers to take part in the dialogue, opening doors to further growth and collaboration.

\section{Acknowledgements}

The authors would like to acknowledge the generous support of the Ministry of Social Affairs Staff and the Syrian Project Desk; the Lebanese fieldworkers from all regions and especially fieldworkers from El-Marj and Rachaya, and Mr. Hussein Salem-region director. Their wonderful and compassionate work on a daily basis to alleviate suffering and support communities through the horrible realities of war and trauma is stellar! Without them, our work could not see the light. The authors would also like to thank Ms. Sama Khair for her collaboration efforts and field visits to the project, The Chester Pierce Division of Global Psychiatry at MGH and Dr. Christina Borba for data analysis and as co-authors on additional manuscripts detailing the results above.

\section{Conflict of Interest}

The authors declare that there is no conflict of interests regarding the publication of this paper.

\section{References}

Abou-Saleh, M. T., \& Hughes, P. (2015). Mental health of Syrian refugees: Looking backwards and forwards. The Lancet Psychiatry, 870-871. http://dx.doi.org/10.1016/S2215-0366(15)00419-8

Amos: Syrian Refugees Make up 25 to 30 Percent of Lebanon's Population. (2015, March 7). Retrieved from Naharnet: http://www.naharnet.com/stories/en/170438

Ballout, D. (2015, January 4). Ballout, D. (2014). Lebanon to require visas for Syrians as refugees strain country: Foreign workers crowd out domestic labor. The Wall Street Journal. Retrieved from http://www.wsj.com/articles/lebanon-to-require-visas-for-syrians-as-refugees-strain-country-1420418670

Bilukha, O., Jayasekaran, D., Burton, A., Faender, G., King'ori, J., Amiri, M., . . Leidman, E. (2014). Nutritional status of women and child refugees from Syria-Jordan, April-May 2014. MMWR Morb Mortal Wkly Rep, 638-9.

Butler, R. N. (1983). Ageism: A foreword. Journal of Social Issues, 8-11. http://dx.doi.org/10.1111/j.1540-4560.1980.tb02018.x

Coutts, A., Fouad, F. M., \& Batniji, R. (2013). Assessing the Syrian Health Crisis in Lebanon. Lancet, e9. http://dx.doi.org/10.1016/s0140-6736(13)60863-6

Crisis Group. (2013). Too Close for Comfort: Syrians in Lebanon. Brussels: International Crisis Group. Retrieved January 5, 2016, from http://www.crisisgroup.org/ /media/Files/ Middle\%20East\%20North\%20Africa/Iraq\%20Syria\%20Lebanon/Lebanon/141-too-close-for-comfort-syria ns-in-lebanon.pdf

Cultural Orientation Resource Center. (2014, November 1). Refugees from Syria. Retrieved from Cultural Orientation Resource Center: http://www.culturalorientation.net/learning/backgrounders

Dahi, O. S. (2013). Breaking Point: The Crisis of Syrian Refugees in Lebanon. Washington DC: Middle East Report. Retrieved February 2016, from http://www.merip.org/mero/mero092513

Desperate and Vulnerable, Some Syrian Refugees Turn to Prostitution. (2013). Retrieved from http://www.dailystar.com.lb/News/Middle-East/2013/Mar-11/209548-desperate-and-vulnerable-some-syrian -refugees-turn-to-prostitution.ashx

From the field: Syrian refugees in Lebanon risk their lives for medical treatment. (2014). Retrieved from https://www.amnesty.org/en/latest/news/2014/03/syrian-refugees-lebanon-risk-lives-medical-treatment/

Galvin, J., Benson, H., Deckro, G., Fricchione, G., \& Dusek, J. (2006). The relaxation response: Reducing stress and improving cognition in healthy aging adults. Complementary Therapies in Clinical Practice, 186-91. 
http://dx.doi.org/10.1016/j.ctcp.2006.02.004

Harissi, M. A. (2015). Lebanon imposes visas on Syrians for first time. Retrieved from United Nations High Commission for Refugees: http://www.unhcr.org/cgi-bin/texis/vtx/refdaily?pass=52fc6fbd5\&id=54aa2ef98

Harvard Humanitarian Intitiative. (2014, November 1). Publications: Harvard Humanitarian Initiative. Retrieved from Harvard Humanitarian Initiative: http://hhi.harvard.edu

Hodeib, M. (2014, July 5). Bassil Warns Against Syrian Refugee Camps. The Daily Star, pp. 5-7. Retrieved from http://www.dailystar.com.lb/News/Lebanon-News/2014/Jul-05/262746-bassil-warns-against-syrian-refugeecamps. ashx\#axzz37IHVl3Ly

IRIN News Middle East. (2012, August 20). Retrieved from IRIN News: $\mathrm{http} / / / \mathrm{www}$.irinnews.org/report/96136/briefing-the-mounting-syrian-refugee-crisis

ISIS Commander killed in Arsal Clashes: Report. (2014, August 5). Retrieved from Daily Star Lebanon: http://www.dailystar.com.lb/News/Lebanon-News/2014/Aug-05/266148-isis-commander-killed-in-arsal-cla shes-report.ashx

Kariuki, F. (n.d.). Conflict Resolution by Elders in Africa: Successes, Challenges and Opportunities. Retrieved from https://www.ciarb.org/docs/default-source/centenarydocs/speaker-assets/francis-kariuki.pdf?sfvrsn=0

Khazaal, C. (2015). Syrian Refugees: Prostitution Rises When Aid Fails. Retrieved from http://www.huffingtonpost.com/chaker-khazaal/syrian-refugees-prostitut_b_6532098.html

Krishnan, K., Levy, R., Wagner, H., Chen, G., Gersing, K., \& Doraiswamy, P. (2001). Informant-rated cognitive symptoms in normal aging, mild cognitive impairment, and dementia. Initial development of an informant-rated screen (Brief Cognitive Scale) for mild cognitive impairment and dementia. Psychopharmacology Bulletin, 20-23. Retrieved from https://www.nia.nih.gov/research/cognitiveinstrument/brief-cognitive-scale\#sthash.b4dijvMy.dpu

Laskowski, K. (2015, October). Addressing Mental Health and Psychosocial Needs in Emergencies.

McConnell, A. (2014, September 30). Syria's oldest refugees. Retrieved from http://tracks.unhcr.org/2014/09/syrias-oldest-refugees/

Mercy Corps. (2016, January 1). Quickfacts: What you need to know about the Syria crisis. Retrieved from http://www.mercycorps.org/articles/turkey-iraq-jordan-lebanon-syria/quick-facts-what-you-need-know-abo ut-syria-crisis

Nebehay, S. (2014, July 14). Syrian refugees, sectarian tensions endanger Lebanon: UN. Retrieved from http://www.dailystar.com.lb/News/Lebanon-News/2014/Jul-14/263824-syrian-refugees-sectarian-tensions-e ndanger-lebanon-\%5Dun.ashx\#ixzz3CofaNMO8

Park, E. R., Traeger, L., Vranceanu, A.-M., Scult, M., Lerner, J. A., Benson, H., . . Fricchione, G. L. (2013). The Development of a Patient-Centered Program Based on the Relaxation Response: The Relaxation Response Resiliency Program (3RP). Psychosomatics, 165-174. http://dx.doi.org/10.1016/j.psym.2012.09.001

Pearson Symptom Checklist 90 Revised. (1994, January). Retrieved from http://www.pearsonclinical.com/psychology/products/100000645/symptom-checklist-90-revised-sc190r.htm 1?Pid=PAg514\#tab-details

Reese Masterson, A., Usta, J., Gupta, J., \& Ettinger, A. (2014). Assessment of reproductive health and violence against women among displaced Syrians in Lebanon. BMC Womens Health, 25. http://dx.doi.org/10.1186/1472-6874-14-25

Sadavoy, J., Lazarus, L. W., Jarvik, L. F., \& Grossberg, G. T. (1997). Comprehensive Review of Geriatric Psychiatry-II. Washington, DC: American Psychiatric Press, Inc.

Second Shift Opens School Doors to Syrian Kids. (2014). Retrieved from http://www.dailystar.com.lb/News/Lebanon-News/2014/Mar-19/250662-second-shift-opens-school-doors-t o-syrian-kids.ashx

Shreif, H. (2014, September 9). Backlash against Syria refugees after Lebanon soldiers killed. Retrieved from http://news.yahoo.com/backlash-against-syria-refugees-lebanon-soldiers-killed-060028530.html; ylt=A0L EVi9arJZWBnUAjDMnnIIQ; ylu=X3oDMTEyZmVrazloBGNvbG8DYmYxBHBvcwMxBHZ0aWQDQjE XMTVfMQRzZWMDc3I-

Snyder, D. (2011, April 10). Learning from the elder wisdom circle. Retrieved from 
http://www.guideposts.org/blog/learning-from-the-elder-wisdom-circle

Strong, J., Varady, C., Chahda, N., Doocy, S., \& Burnham, G. (2015). Health status and health needs of older refugees from Syria in Lebanon. Conflict and Health, 12. http://dx.doi.org/10.1186/s13031-014-0029-y

The Benson Henry Institute 3 RP SMART Program. (2016, January 14). Retrieved from http://www.bensonhenryinstitute.org/3rp

The UN refugee agency. (2015, December 31). UNHCR: Syria regional refugee response. Retrieved from $\mathrm{http}: / /$ data.unhcr.org/syrianrefugees/regional.php

UN says Syria refugee crisis worst since Rwanda. (2013, July 15). Retrieved January 2016, from http://www.bbc.com/news/world-middle-east-23332527

UNHCR. (2013, December 3). LEBANON: UNHCR chief Guterres highlights the plight of Syrian children. Retrieved from http://www.unrefugees.org.au/news-and-media/news-headlines/lebanon-unhcr-chiefguterres-highlights-the-plight-of-syrian-children

UNHCR. (2016, January 2016). Syrian Regional Refugee Response. Retrieved from http://data.unhcr.org/syrianrefugees/regional.php

United Nations High Commission for Refugees. (2014, April 3). UNHCR: The UN Refugee Agency. Retrieved from UNHCR: http://www.unhcr.org/533c15179.html

USA International Business Publications. (2012, March 3). Lebanon Country Study Guide: Strategic Information and Developments. United State : Intl Business Pubns USA.

World Health Organization. (2008). Social determinants of health in countries of conflict: A perspective from the Eastern Mediterranean Region. WHO Regional Publications, Eastern Mediterranean Series 32. Retrieved from http://applications.emro.who.int/dsaf/dsa955.pdf

\section{Copyrights}

Copyright for this article is retained by the author(s), with first publication rights granted to the journal.

This is an open-access article distributed under the terms and conditions of the Creative Commons Attribution license (http://creativecommons.org/licenses/by/3.0/). 